\section{Assessment of Yellow-fleshed Kiwifruit (Actinidia chinensis 'Hort16A') Quality in Pre- and Post-harvest Conditions Using a Portable Near-infrared Spectrometer}

\author{
Jinquan Feng ${ }^{1}$, Andrew V. McGlone, Mike Currie, Chris J. Clark, \\ and Bob R. Jordan \\ The New Zealand Institute for Plant \& Food Research Limited, Private Bag \\ 92169, Auckland 1142, New Zealand
}

Additional index words. dry matter, soluble solids, flesh hue, FANTEC ${ }^{\text {TM }}$ FQA-NIRGUN, field measurement, temperature, ambient light, model transfer

\begin{abstract}
Dry matter content (DM), soluble solids content (SSC), and flesh hue (FH) are important quality attributes of yellow-fleshed kiwifruit (Actinidia chinensis 'Hort16A'). Rapid non-destructive measurement tools enable effective assessment of quality attributes in the field or in packhouses and offer the potential for selective harvesting and differential postharvest treatments. This study investigates a few practical issues for use of one such tool, a portable near-infrared spectrometer, the FANTEC ${ }^{T M}$ FQANIRGUN. Experimental results indicated that the precision of the NIRGUN in predicting the DM, SSC and FH of 'Hort16A' kiwifruit, given as the root mean square error of calibration (RMSEC), is $0.6 \%, 0.9 \%$ and $1.4^{\circ}$, respectively, and is similar to that reported for standard laboratory benchtop spectrometers. These levels of precision are good enough to distinguish differences in fruit quality between fruit from different vines. However, this is only possible when measurements are carried out under similar conditions either within a short period of time in the field when fruit temperature is stable or in a temperature-controlled laboratory. The calibration developed on one instrument could be transferred to another instrument, but bias correction is necessary after the calibration transfer. Hence, the absolute accuracy of predictions from the NIRGUN is limited by significant and variable bias offset issues, particularly for field measurements when fruit are on the vine.
\end{abstract}

'Hort16A' (Actinidia chinensis Planch. var. chinensis) is a yellow-fleshed kiwifruit cultivar that is marketed globally as ZESPRI ${ }^{\circledR}$ GOLD kiwifruit. SSC at harvest is an indicator of fruit maturity, and DM content reflects the potential SSC at "eating ripe," i.e., when starch reserves in the berry have been converted to

Received for publication 17 June 2010. Accepted for publication 13 Oct. 2010.

This study was funded by ZESPRI International Limited.

We thank Alistair Mowat of ZESPRI Innovation Ltd. and Shirley Miller of Plant \& Food Research for their efforts to initiate and support this project. We also thank Daniel Mathieson of ZESPRI Group Ltd. and Tim Torr of Apata Ltd. for arranging access to the NIRGUNs; AgFirst BOP Ltd. and Linda Boyd of Plant \& Food Research for sharing fruit and data; Yuko Maeda of FANTEC Research Institute for technical advice; and Dr. Nihal DeSilva of Plant \& Food Research for assistance in statistical data analysis. We also thank Alison Duffy and Philip Martin of Plant \& Food Research for assistance with destructive measurements.

Use of trade names does not imply an endorsement of the products named or criticism of similar ones not named.

${ }^{1}$ To whom reprint requests should be addressed; e-mail Ringo.Feng@plantandfood.co.nz. sugars during fruit softening. FH is an important quality parameter for 'Hort16A', because its yellow color is a primary factor in the appeal of the fruit to the consumer (Martin and Luxton, 2005). Flesh color changes from green to yellow as the fruit matures. However, there is still a considerable degree of variability present in the properties of the fruit at harvest (Schaare and Fraser, 2000).

Fruit variability at harvest leads to problems in post-harvest handling. For example, 1 of 2 weeks of conditioning at $5{ }^{\circ} \mathrm{C}$ is used for fruit with $\mathrm{FH}$ values above $105^{\circ}$. This enables the flesh degreening process to occur but can result in excessive softening of fruit with $\mathrm{FH}$ below $103^{\circ}$. A line of fruit may have a mix of FH. Thus, identification of fruit with lower FH (which are generally associated with more advanced maturity) in the orchard, coupled with staged selective harvesting of the mature fruit, would lead to reduced variation in quality and overall improvement in the quality of the harvested crop. In addition, the ready identification of poorly performing or slowly maturing vines would enable targeted remedial measures to be undertaken.

Near-infrared (NIR) spectroscopic tools suitable for orchard use would enable fast, non-destructive, and effective monitoring of fruit maturity on-vine. The color and taste attributes of 'Hort16A' are currently determined in the New Zealand kiwifruit industry by destructive measurement of FH, DM, and SSC. Laboratory-based NIR spectroscopy on samples of 'Hort16A' kiwifruit post-harvest has demonstrated that it is possible to measure these attributes with prediction errors of $\approx 0.5 \%, 0.9 \%$, and $1.1^{\circ}$ for $\mathrm{DM}, \mathrm{SSC}$, and $\mathrm{FH}$, respectively (Clark et al., 2004). Portable NIR instruments have been developed and used to assess maturity and quality indices of many fruits (Aoki et al., 2010; Costa et al., 2002; Golding et al., 2006; Khuriyati et al., 2004; Kusumiyati et al., 2008; Saranwong et al., 2003a, 2003b; Zude et al., 2008). However, the performance of these instruments under different temperature and light conditions has not been studied rigorously for in situ measurements of 'Hort16A' kiwifruit in the field.

The study reported here evaluated the performance of a commercially available FQA-NIRGUN released by the FANTEC Research Institute (Shizuoka, Japan) with an attempt to determine possible influences of temperature and light conditions. The possibility of transferring predictive models developed on one NIRGUN to another NIRGUN was also tested.

\section{Materials and Methods}

\section{The instrument}

The FQA NIRGUN (FANTEC Research Institute) is a gun-shaped NIR spectrophotometer weighing less than $1 \mathrm{~kg}$ (Fig. 1) that can be easily operated in both the field and laboratory. This instrument was chosen because it was commercially available back in 2005 when this study started and it fulfilled the needs for outdoor use with a small-size, lightweight, rechargeable battery, weatherresistant, and easy data handling (Saranwong et al., 2003a, 2003b). The head of the NIRGUN contains apertures for the light source (a small halogen lamp) and detector and is arranged so that an interactance measurement is made on the fruit. A spectral measurement, made by pressing a trigger button in the handle, consists of a series of light intensity measurements made at 2-nm intervals between $588 \mathrm{~nm}$ and $1092 \mathrm{~nm}$ (256 data points per spectrum). Up to three fruit quality attributes can be predicted simultaneously from the spectrum using onboard models, and results are displayed immediately on the NIRGUN's LCD screen. With a fully charged battery, the NIRGUN can make 2000 measurements when operating in the standalone mode. The on-board memory is able to store 5000 predicted values or spectra and predicted values for 500 measurements, which can be downloaded to a computer for offline analysis.

\section{Measurement procedure}

The NIRGUN was placed on the fruit in such a way that the light source shone onto the blossom side of the fruit with the detector facing the middle (Fig. 1). In this position, the curvature of the fruit formed a good fit with the geometry of the NIRGUN head. Care was taken to make measurements on the flattest 


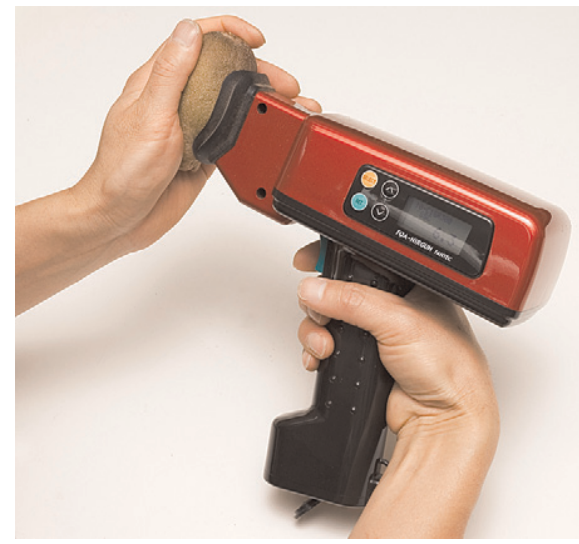

Fig. 1. Measurement of 'Hort16A' kiwifruit using a FANTEC ${ }^{\text {TM }}$ FQA-NIRGUN

side of the fruit to maximize the light-sealing capability of the external rubber seal around the head. The NIRGUN was held on the fruit with moderate pressure to ensure that the internal rubber ring that surrounds the detector aperture was firmly against the fruit surface, thus preventing source light directly entering the detector without having first passed through the fruit. This measurement procedure also proved to be easy and practical for orchard use while fruit were still on the vine.

An integration time of $30 \mathrm{~ms}$ was selected based on preliminary measurement of a range of typical 'Hort16A' kiwifruit so that the spectral peak height occupied $\approx 50 \%$ of the full range (as recommended by FANTEC). It takes $\approx 2 \mathrm{~s}$ to complete a measurement.

\section{Referencing}

Referencing is a process that monitors instrument performance and ensures that it continues to operate in a stable mode. A reference spectrum taken on the supplied white reference tile (specific to each instrument) is preinstalled in memory, and it is not necessary to do referencing after every measurement. However, referencing needs to be redone after replacing the halogen lamp or if the instrument has not been used for more than $90 \mathrm{~d}$. The integration time for referencing was fixed at $15 \mathrm{~ms}$ and is independent of the integration time set for fruit measurement. There is no information about the dark reference in the instrument manual. However, the same baseline and white reference spectrum appear when the spectrum from fruit is displayed using the vendor-supplied software. We can download absorbance and first and second derivative data, but not the raw data. It is possible that a dark reference is taken every time when the white reference is being renewed.

\section{Development of calibration models}

Calibrations were generated using the proprietary software "Ca_Maker" supplied with the NIRGUN. By default, calibration was performed using the second derivative of the absorbance spectra generated with what appears to be a Norris Derivative scheme (Hopkins, 2001) with segment, gap, and smoothing sizes of 14, 0, and $20 \mathrm{~nm}$, respectively. Segment is the wavelength range used to apply second differential calculus on the spectrum. Gap is the distance between the last wavelength in one segment and the first wavelength in the next segment. Smoothing size is the wavelength range used for smoothing (Ca_Maker uses moving averages for smoothing). These settings can be altered to suit particular applications using more advanced calibration software called "Professional Ca_Maker" available from FANTEC by special request. The software used multiple linear regressions for calibration modeling, searching for the best combination of up to five wavelengths over the truncated spectral range ( 700 to $950 \mathrm{~nm}$ by default but can be altered when using "Professional Ca_Maker"). Calibrations were judged using the standard measures of RMSEC and $R^{2}$, the coefficient of determination.

Three different data subsets of 'Hort16A' fruit were collected for preliminary investigations, which were then combined to make a full calibration data set covering the expected variation resulting from differences in temperature and orchard location.

The first calibration subset consisted of 300 fruit harvested from the Te Puke Plant \& Food Research Orchard in the Bay of Plenty (North Island), New Zealand's major kiwifruit production region. The fruit were equilibrated to $20{ }^{\circ} \mathrm{C}$ in a laboratory before NIR spectra were collected. This was followed by destructive assessments of DM, SSC, and FH using standard industry techniques as outlined in Schaare and Fraser (2000) and McGlone et al. (2002). Briefly, FH was measured using a Minolta Chroma Meter (CR-300, D65 light source, calibrated with a white calibration plate; Minolta, Japan) after the removal of skin and flesh to a depth of $\approx 2 \mathrm{~mm}$. Two color measurements were made on each fruit at two sides at $90^{\circ}$ to each other along the equator of the fruit. The two readings measured from each fruit were averaged to give one value for each fruit. Soluble solids content was measured using a digital refractometer (Atago, Tokyo, Japan; $0 \%$ to $20 \%$ ) with juice squeezed from the blossom and stem ends separately, and the two readings were averaged to give one value for each fruit. DM was measured using a slice $\approx 3 \mathrm{~mm}$ in thickness (including skin, flesh, seeds, and core tissues) cut along the equator of each fruit. The slice was weighed immediately after cutting and then after dried to constant weight (typically $24 \mathrm{~h}$ at $65^{\circ} \mathrm{C}$ ).

Two NIRGUN measurements were taken on opposite sides of each fruit, giving a total of 600 spectra. All 600 spectra were used for initial calibration with each destructive measurement being matched to the corresponding pair of spectra from the same fruit.

The second calibration set consisted of a subsample of 90 fruit in addition to the 300fruit data calibration subset described previously. These fruit were randomly assigned to two different batches of 45 fruit each. The first batch was warmed to $20{ }^{\circ} \mathrm{C}$ for the first NIRGUN measurement, then cooled to $15^{\circ} \mathrm{C}$ and re-measured, and finally cooled to $8{ }^{\circ} \mathrm{C}$ and remeasured a third time. These repeated measurements were made on the same two spots on each fruit. The second batch was first cooled to $8{ }^{\circ} \mathrm{C}$ and measured before warming to $15{ }^{\circ} \mathrm{C}$ and finally to $20^{\circ} \mathrm{C}$ for repeat measurements. NIRGUN measurements were carried out once stable fruit temperatures had been reached after $\approx 3$-h equilibration at each temperature (Feng et al., 2002). In all cases, the NIRGUN was maintained at the same temperature as the fruit themselves to replicate conditions that would be expected for field measurements. After the NIR measurements, these fruit were then equilibrated to $20^{\circ} \mathrm{C}$ for destructive assessments of DM, SSC, and FH.

The third calibration set consisted of 45-fruit samples from six grower lines from three different production regions within New Zealand: Nelson, Bay of Plenty, and Kerikeri. On arrival, moisture and dirt on fruit surfaces were removed by hand wearing a cotton glove. Fruit were then packed into single-layer kiwifruit trays and held at $20^{\circ} \mathrm{C}$ to allow surfaces to dry completely before NIRGUN measurements were undertaken. This data set was designed to test whether orchard location had a significant effect on NIR prediction and to allow the calibration model to account for variation between orchards.

The master calibration was developed using a combined data set containing 990 observations, in which 180 observations were from Set 1, 360 observations from Set 2 (NIR measurement at 8,15 , and $20^{\circ} \mathrm{C}$ ), and 450 observations from Set 3. Some data from each of the three subsets had to be eliminated from the combined master, Because the calibration software supplied with the NIRGUN only allows a maximum of 1000 observations. The selection of observations was arbitrary based on measurement condition and fruit variability to maximize the coverage.

\section{Performance of the master calibration in on-vine fruit measurement}

The master calibration based on the combined master calibration data set was loaded onto the NIRGUN and used to measure fruit on vines in the field. Ten fruit per vine were selected from each of nine kiwifruit vines in the Plant \& Food Research Te Puke orchard. The measurements were made on a sunny fall day during the main harvest season in 2005 $(\approx 210 \mathrm{~d}$ after full bloom). The temperature, relative humidity, and radiation during the day were recorded at a weather station in the orchard. Each fruit was measured three times during the day, while it remained on the vine, using the NIRGUN. Fruit were subsequently harvested after sunset and the NIR measurements were repeated again in a laboratory at $20{ }^{\circ} \mathrm{C}$ before destructive measurement of DM, SSC, and FH.

\section{Performance of the master calibration in a subsequent year using another NIRGUN}

Encouraging results from experiments in 2005 led to the purchase of six FANTEC ${ }^{\text {TM }}$ FQA-NIRGUN units by New Zealand packhouses in 2006. In 2007, the performance of the predictive models established in 2005 was tested under a range of temperature and light conditions with one of these new units. 
A random sample of 60 fruit was harvested from girdled vines and 40 fruit from control vines during the main harvest season (4 May 2007). Fruit from each treatment were randomly assigned into four groups of 25 fruit (15 fruit from girdled vines and 10 fruit from control vines) to test the effect of temperature and light conditions.

Measurement at different combinations of fruit and instrument temperatures. Fruit of the first group were placed in storage at $10^{\circ} \mathrm{C}$, whereas those of the second group were placed in an air-conditioned laboratory at $20{ }^{\circ} \mathrm{C}$. NIRGUN measurements were carried out twice. The first measurement was made when the instrument temperature was $\approx 20{ }^{\circ} \mathrm{C}$; the NIRGUN (at $20^{\circ} \mathrm{C}$ ) was taken to where the fruit were kept and the measurements were completed within $3 \mathrm{~min}$. The second measurement was made when the instrument temperature was at $\approx 10{ }^{\circ} \mathrm{C}$; again the NIRGUN (at $10{ }^{\circ} \mathrm{C}$ ) was taken to where the fruit were kept and the measurements were completed within $3 \mathrm{~min}$. On each measurement occasion, a single spectrum was taken on orthogonal sides of the fruit at (i.e., the flat side and curved side) and predicted values were averaged to give a single reading for each fruit. Fruit kept at $10{ }^{\circ} \mathrm{C}$ were equilibrated to $20^{\circ} \mathrm{C}$ before destructive measurement of DM, SSC, and FH. This produced a matrix of two instrument temperatures and two fruit temperatures to investigate the effect of temperature on measured values.

Measurement at different ambient light conditions. Fruit from the remaining two 25fruit groups were stored at $0{ }^{\circ} \mathrm{C}$ for $2 \mathrm{~d}$ and then equilibrated for $5 \mathrm{~h}$ at $20^{\circ} \mathrm{C}$ before NIR spectra were obtained. NIRGUN measurements were taken twice before destructive measurement of DM, SSC, and FH, once under weak ambient light (scattered light from windows when all the lights in the laboratory were turned off) and again under strong ambient light $(800 \mathrm{~mm}$ under two 58-W Philips daylight fluorescent tubes; Philips, Holland). This was to test if ambient light intensity had a significant effect on predicted values.

\section{Data analysis}

The relationship between NIRGUN predictions and destructively measured values was analyzed using regression and general linear model procedures (REG, MENS, and GLM) with the software package SAS Version 8.2 (SAS Institute Inc., Cary, NC). Predictions were judged on the basis of the standard statistics of root mean square error of prediction (RMSEP), bias (the average difference between actual and predicted values), the SE of prediction (SEP, equivalent to $\sqrt{\left(R M S E P^{2}-B I A S^{2}\right)}$, and $R^{2}$. The two predicted values from repeated measurements on each fruit were averaged to give a single predicted value before these analyses were undertaken.

\section{Results}

Calibration models. The initial calibration subset $(\mathrm{N}=600$ spectra from 300 fruit) delivered only moderately performing models for DM and $\mathrm{FH}$ and poor models for SSC, possibly because of the fairly narrow range of parameter distributions involved (Table 1). The initial calibration was then applied to the other two calibration data sets to investi-

gate the effect of fruit temperature and orchard location on NIR measurements.

A strong temperature effect was readily apparent in the second calibration data set, particularly for SSC predictions. NIR-predicted values for DM and SSC increased as

Table 1. Statistics of the initial calibration based on 600 spectra measured at $20{ }^{\circ} \mathrm{C}$ on 300 ' $\mathrm{Hort} 16 \mathrm{~A}$ ' kiwifruit harvested from one orchard (initial calibration experiment) and the master calibration based on 990 spectra measured at different temperatures on fruit harvested from different orchards (combined data set from three calibration experiments).

\begin{tabular}{lccccccr}
\hline & \multicolumn{3}{c}{ Initial calibration } & & \multicolumn{3}{c}{ Master calibration } \\
\cline { 2 - 3 } Attribute & RMSEC & $R^{2}$ & Mean \pm SD & & RMSEC & $R^{2}$ & Mean \pm SD \\
\hline Dry matter content (\%) & 0.67 & 0.79 & $16.0 \pm 1.50$ & & 0.60 & 0.85 & $16.4 \pm 1.52$ \\
Soluble solids content (\%) & 0.91 & 0.53 & $8.1 \pm 1.33$ & & 0.90 & 0.90 & $10.5 \pm 2.88$ \\
Flesh hue $\left(^{\circ}\right)$ & 1.38 & 0.77 & $104.6 \pm 2.93$ & & 1.39 & 0.86 & $105.1 \pm 3.67$ \\
\hline
\end{tabular}

RMSEC $=$ root mean square error of calibration, $R^{2}=$ coefficient of determination.
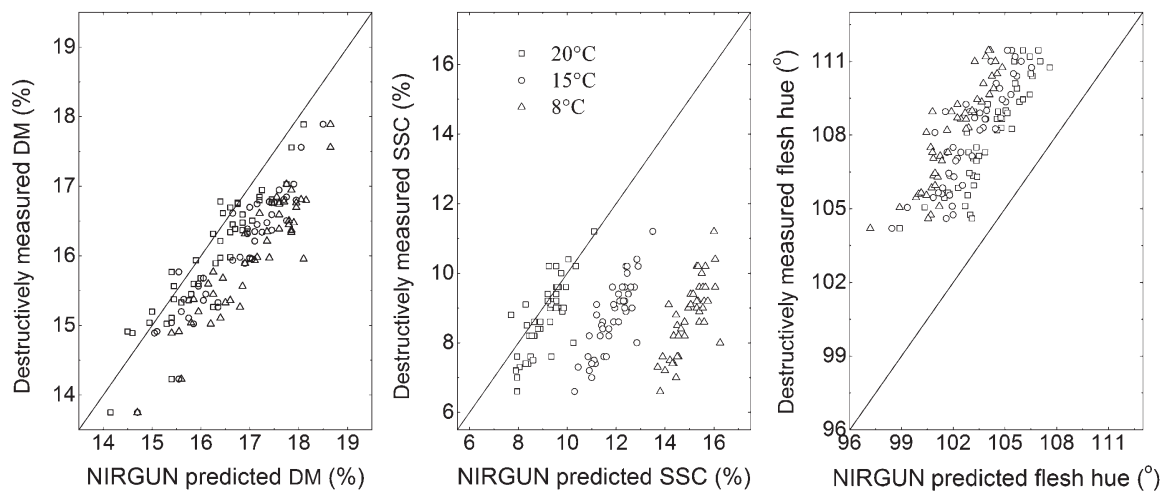

Fig. 2. Effect of temperature on NIRGUN measurements of 'Hort16A' kiwifruit dry matter content (DM), soluble solids content (SSC), and flesh hue using the initial calibration established based on the first calibration data set measured at $20^{\circ} \mathrm{C}$ on 300 'Hort16A' kiwifruit harvested from one orchard (see Tables 1 and 2 for details). Fruit were measured as they changed from low to high temperature. The NIRGUN was maintained at the same temperature as the fruit themselves. Similar results for the reverse change have been omitted for clarity.

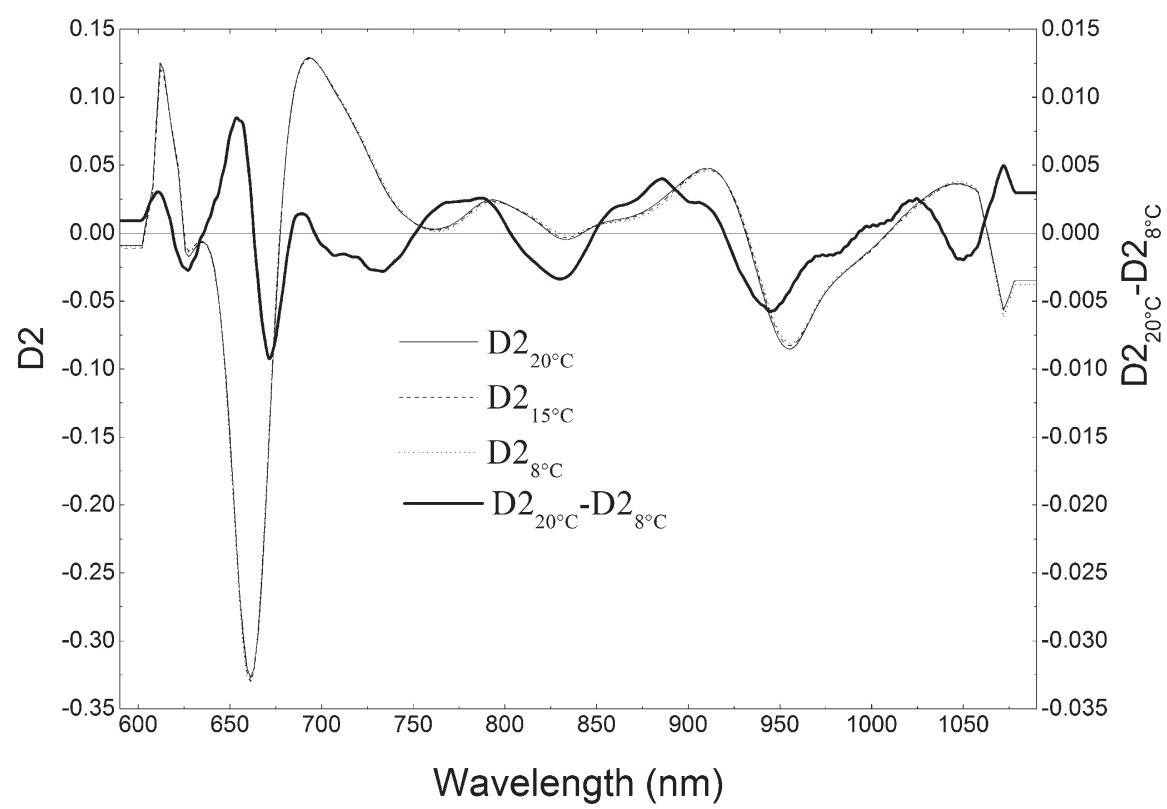

Fig. 3. Second derivative (D2) spectra of the same 90 'Hort16A' kiwifruit measured at three different temperatures (both the instrument and fruit were equilibrated to a specified temperature to replicate conditions that would be expected for field measurements). The difference between D2 values measured at 20 and $8{ }^{\circ} \mathrm{C}\left(\mathrm{D} 22{ }^{\circ}{ }^{\circ} \mathrm{C}-\mathrm{D} 2{ }_{8}{ }^{\circ} \mathrm{C}\right)$ was plotted at 10 times scale for clarity. 
temperature decreased. On the other hand, NIR-predicted values for FH decreased as temperature decreased (Fig. 2). In case of DM and SSC, there was almost no bias between destructively measured and NIRGUN-predicted values at $20^{\circ} \mathrm{C}$ for either parameter. However, there was a significant bias for $20^{\circ} \mathrm{C} \mathrm{FH}$ determination. NIR-predicted $\mathrm{FH}$ values at $20^{\circ} \mathrm{C}$ were $\approx 3{ }^{\circ} \mathrm{C}$ lower than destructively measured values. This might have been caused by a systematic error in the destructively measured FH values. Destructively measured FH value could be affected by thickness of the removed skin and inaccurate calibration of the Minolta colorimeter. Fortunately, the relative difference between fruit was not changed, i.e., bias of NIRGUN-predicted values did not appear to be dependent on measured values.

Comparison between NIR spectra taken at three temperature conditions indicated that temperature has a significant influence in the second derivative spectra, particularly at the chlorophyll absorption region of $\approx 680 \mathrm{~nm}$ and the water absorption region $\approx 950 \mathrm{~nm}$ (Fig. 3).

Bias resulting from orchard location was not as marked as the temperature effect (Fig. 4).

The final master calibration results (Table 1) based on combined data from all three subsets were encouragingly good with high $R^{2}$ values $(0.85,0.9$, and 0.86 for $\mathrm{DM}, \mathrm{SSC}$, and $\mathrm{FH}$, respectively) and reasonable RMSEC values $(0.60,0.9$, and 1.39 for DM, SSC, and $\mathrm{FH}$, respectively) compared with the statistics produced for 'Hort 16A' fruit using a benchtop NIR unit operating under standardized conditions (Clark et al., 2004; Schaare and Fraser, 2000).

The wavelengths and coefficients to calculate fruit attributes from second derivative spectra are listed in Table 2. The coefficients and wavelengths used in the master calibration are different from those used in the initial calibration. In general, the wavelengths used in the master calibration had smaller temperature impact factors (difference between second derivative spectra measured at 20 and $8{ }^{\circ} \mathrm{C}$ on the same 90 fruit expressed as a percentage relative to the average spectra at the two temperatures). For example, temperature impact factors were on average over $50 \%$ smaller for the master calibrations and always the initial calibrations had the wavelengths with the single largest temperature impact factor (Table 2). Therefore, it is perhaps not surprising that the master calibration is less sensitive to temperature changes.

Performance of the master calibration with on-vine fruit measurement in the field. Environmental conditions in the orchard showed the expected diurnal variation in temperature, relative humidity, and radiation flux (Fig. 5). The NIRGUN predictions for the 90 fruit from nine vines were well correlated with destructively measured quality attributes $\left(R^{2} \approx 0.7\right.$ to 0.9$)$. However, the predictions also showed a similar diurnal variation with bias values varying with time and generally peaking at the $1400 \mathrm{HR}$ measurement (Table 3).

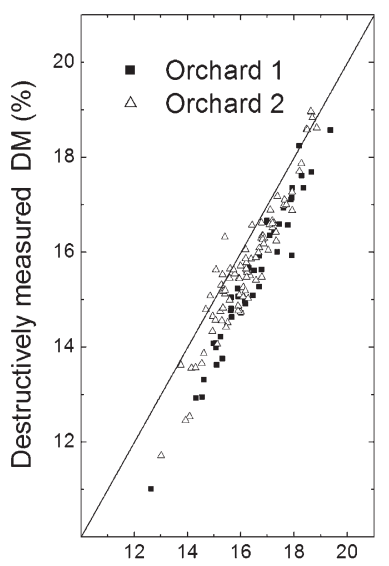

NIRGUN predicted DM (\%)

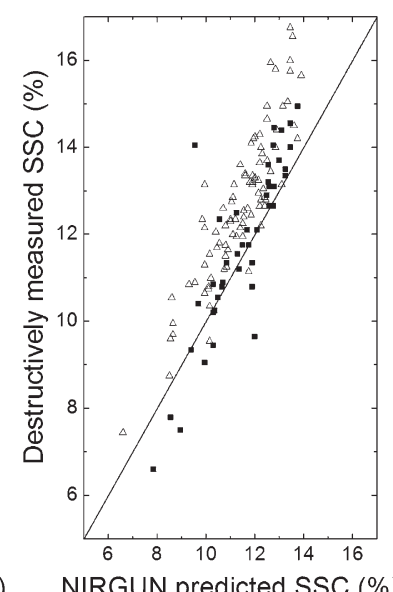

NIRGUN predicted SSC (\%)

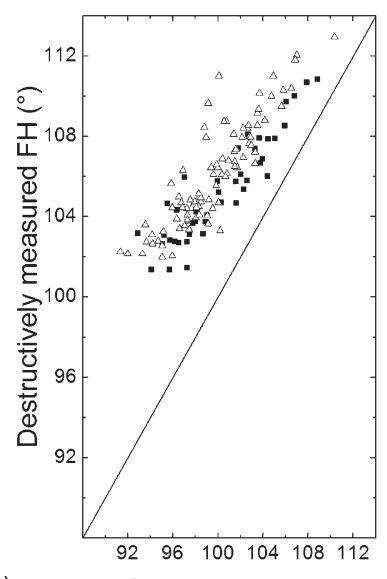

NIRGUN predicted $\mathrm{FH}\left({ }^{\circ}\right)$

Fig. 4. Effect of orchard location on NIRGUN measurement of dry matter content (DM), soluble solids content (SSC), and flesh hue (FH) of 'Hort16A' kiwifruit using the initial calibration established based on the first calibration data set (see Tables 1 and 2 for details). The measurement was carried out at $20^{\circ} \mathrm{C}$ with the same temperature for both fruit and the NIRGUN. Data from two orchards are presented, whereas those from the other four orchards have been omitted for clarity. Solid lines represent 1:1 lines.

Table 2. Model coefficients of the initial calibration based on 600 spectra measured at $20{ }^{\circ} \mathrm{C}$ on 300 'Hort16A' kiwifruit harvested from one orchard (initial calibration experiment) and the master calibration based on 990 spectra measured at different temperatures on fruit harvested from different orchards (combined data set from three calibration experiments). ${ }^{z}$

\begin{tabular}{|c|c|c|c|c|}
\hline \multirow[b]{2}{*}{ Attribute } & \multicolumn{2}{|c|}{ Initial calibration } & \multicolumn{2}{|c|}{ Master calibration } \\
\hline & Wavelength (nm) & $\overline{\text { Coefficient }}$ & Wavelength (nm) & Coefficient \\
\hline \multirow[t]{6}{*}{$\overline{\text { Dry matter content }(\%)}$} & Intercept & 20.6 & Intercept & 32.3 \\
\hline & $820(-33.3)^{\mathrm{y}}$ & 774.1 & $720(-2.4)$ & -85.7 \\
\hline & $836(118.9)$ & -222.5 & $752(2.9)$ & 160.8 \\
\hline & $864(21.1)$ & 2242.4 & $828(827.8)$ & 424.0 \\
\hline & $900(5.7)$ & -1033.5 & $872(20.1)$ & 2124.8 \\
\hline & $932(2184.7)$ & 343.5 & $896(7.8)$ & -1129.6 \\
\hline \multirow[t]{6}{*}{ Soluble solids content $(\%)$} & Intercept & 15.4 & Intercept & 25.0 \\
\hline & $700(-0.8)$ & -85.3 & $700(-0.8)$ & -144.8 \\
\hline & $824(-87.5)$ & 850.3 & $816(-18.1)$ & -852.0 \\
\hline & $860(21.7)$ & 1290.7 & $868(20.6)$ & 1826.2 \\
\hline & $888(14.6)$ & -1621.5 & $892(10.6)$ & -1758.7 \\
\hline & $916(2.3)$ & 589.0 & $916(2.3)$ & 867.0 \\
\hline \multirow[t]{6}{*}{ Flesh hue $\left({ }^{\circ}\right)$} & Intercept & 57.4 & Intercept & 75.1 \\
\hline & $708(-1.6)$ & 550.4 & $732(-7.2)$ & 1046.3 \\
\hline & $768(67.7)$ & -761.4 & $752(2.9)$ & -2107.9 \\
\hline & $860(21.7)$ & -2511.0 & $872(20.1)$ & -2766.9 \\
\hline & 888 (14.6) & 2738.8 & 888 (14.6) & 2170.1 \\
\hline & $916(2.3)$ & -1087.4 & $948(8.1)$ & 247.6 \\
\hline
\end{tabular}

${ }^{2}$ Both calibrations were based on the second derivative of the absorbance spectra.

${ }^{y}$ The number in brackets after each wavelength is a temperature impact factor (TIF) calculated as a percentage change in second derivative (D2) spectra based on data from 90 fruit measured at $20{ }^{\circ} \mathrm{C}$ and $8{ }^{\circ} \mathrm{C}\left(\mathrm{TIF}=100 \cdot\left(\mathrm{D} 220{ }^{\circ} \mathrm{C}-\mathrm{D} 2{ }_{8}{ }^{\circ} \mathrm{C}\right) /\left[\left(\mathrm{D} 2{ }_{20}{ }^{\circ} \mathrm{C}+\mathrm{D} 2{ }_{8}^{\circ} \mathrm{C}\right) / 2\right]\right.$.

For the purpose of detecting relative differences between vines, means of DM, $\mathrm{SSC}$, and FH measurements of the nine vines predicted from the NIRGUN ranked almost identically to the means based on destructive measurement regardless of diurnal time (Figs. 6, 7, and 8). Analysis of variance between fruit from different vines based on values predicted from the NIRGUN resulted in similar separation of means compared with that based on destructive measurement because the least significant differences between means were in similar scales.

Model performance in a subsequent year at different temperature conditions. The master calibration developed in 2005 based on combined data sets from three calibration experiments (Table 1) performed well in 2007 when the calibration was loaded onto another NIRGUN. NIRGUN measurement at $20{ }^{\circ} \mathrm{C}$ explained over $95 \%$ of the variance in measured DM, over $82 \%$ of the variance in measured SSC, and over $85 \%$ of the variance in measured $\mathrm{FH}$. The predictions at $10{ }^{\circ} \mathrm{C}$ were similar to that at $20^{\circ} \mathrm{C}$ except for SSC, in which predicted values explained slightly less $(\approx 72 \%)$ than the variance in measured SSC. SEPs were $0.31 \%$ to $0.40 \%$ DM, $0.10 \%$ to $0.18 \% \mathrm{SSC}$, and 0.39 to $0.86^{\circ}$ hue (Fig. 9).

Significant bias existed for all the predictions. The bias for DM was significantly affected by instrument temperature but was unaffected by fruit temperature. The prediction bias was $-0.59 \%$ DM when the NIRGUN 


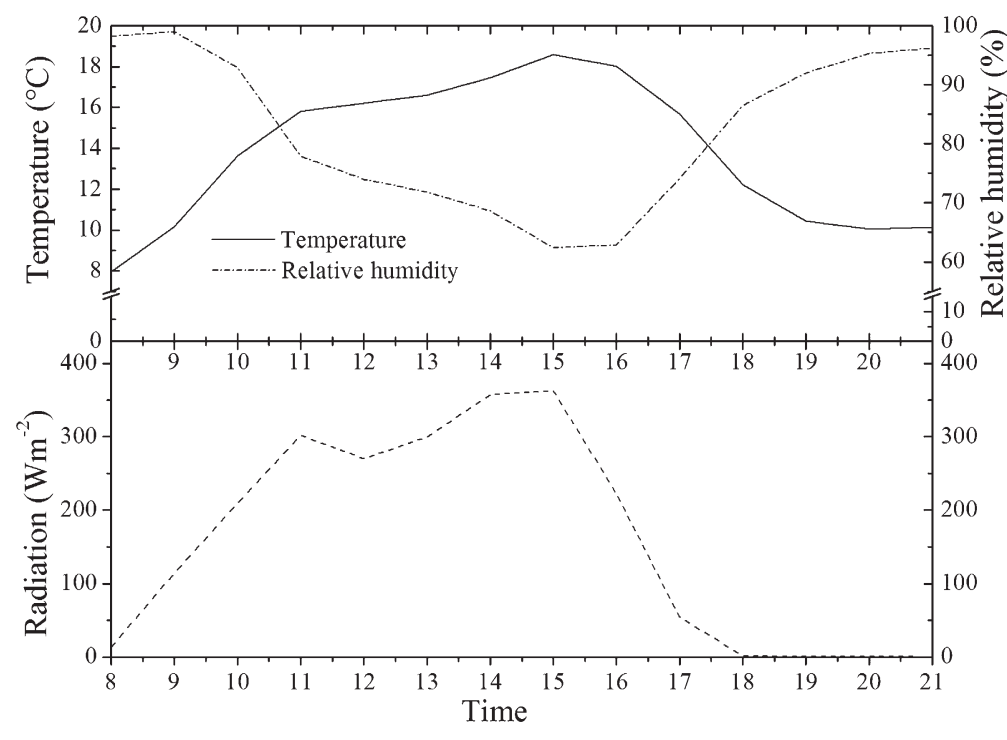

Fig. 5. Temperature, relative humidity, and radiation from the 'Hort16A' kiwifruit orchard on the day that field measurements using the NIRGUN were carried out.

Table 3. Effect of diurnal course on predicting dry matter content, soluble solids content, and flesh hue of 'Hort 16A' kiwifruit $(\mathrm{n}=90)$ using a FANTEC ${ }^{\text {TM }}$ FQA-NIRGUN in the field with the master calibration established based on combined data sets (see Tables 1 and 2 for details).

\begin{tabular}{llcrrrr}
\hline Attribute & \multicolumn{1}{c}{ Time/Place } & RMSEP $^{\mathrm{z}}$ & SEP $^{\mathrm{y}}$ & Bias $^{\mathrm{x}}$ & Slope $^{\mathrm{w}}$ & $R^{2 \mathrm{v}}$ \\
\hline Dry matter content & $1000 \mathrm{HR} /$ field & 0.59 & 0.44 & -0.39 & $0.79^{*}$ & 0.83 \\
$(\%)$ & $1400 \mathrm{HR} /$ field & 1.26 & 0.39 & -1.20 & $0.78^{*}$ & 0.87 \\
Mean $=16.4 \%$ & $1800 \mathrm{HR} /$ field & 0.76 & 0.36 & -0.66 & $0.82^{*}$ & 0.89 \\
$\mathrm{SD}=1.1 \%$ & $2000 \mathrm{HR} /$ laboratory & 0.39 & 0.39 & 0.03 & $0.82^{*}$ & 0.87 \\
Soluble solids content & $1000 \mathrm{HR} /$ field & 1.28 & 1.13 & -0.61 & $0.57^{*}$ & 0.72 \\
$(\%)$ & $1400 \mathrm{HR} /$ field & 1.42 & 1.07 & -0.94 & $0.59^{*}$ & 0.75 \\
Mean $=10.5 \%$ & $1800 \mathrm{HR} /$ field & 1.33 & 1.08 & -0.77 & $0.62^{*}$ & 0.73 \\
$\mathrm{SD}=2.0 \%$ & $2000 \mathrm{HR} /$ laboratory & 1.12 & 1.08 & -0.26 & $0.61^{*}$ & 0.73 \\
Flesh hue $\left({ }^{\circ}\right)$ & $1000 \mathrm{HR} /$ field & 3.64 & 1.61 & -3.26 & 1.06 & 0.77 \\
Mean $=99.3^{\circ}$ & $1400 \mathrm{HR} /$ field & 3.62 & 1.53 & -3.28 & 1.05 & 0.79 \\
$\mathrm{SD}=2.8^{\circ}$ & $1800 \mathrm{HR} /$ field & 3.80 & 1.50 & -3.49 & 1.08 & 0.80 \\
& $2000 \mathrm{HR} /$ laboratory & 2.09 & 1.42 & -1.53 & 1.06 & 0.82 \\
\hline
\end{tabular}

${ }^{\mathrm{z}}$ Root mean square error of prediction.

${ }^{y_{S E}}$ of prediction.

${ }^{\mathrm{x}}$ Average difference between actual and predicted values (measured value-predicted value).

${ }^{\text {w}}$ Slopes of the regression lines with asterisk are significantly different from 1 at $P<0.05$ significance level.

${ }^{v}$ Coefficient of determination.

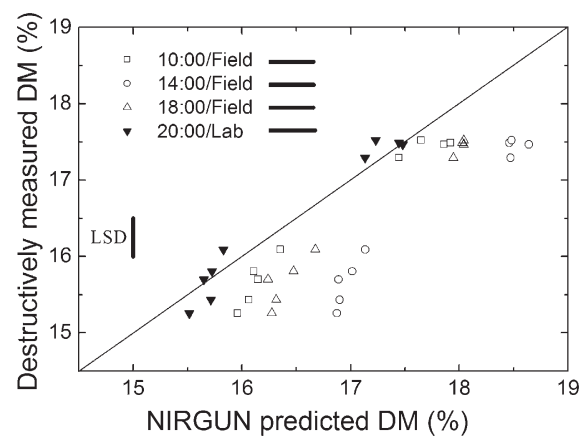

Fig. 6. Comparison between average 'Hort16A' kiwifruit dry matter contents (DM) measured destructively and those predicted from NIRGUN assessments in the field or laboratory at different times during a sunny day. The master calibration was established based on the combined data set (see "Methods") measured using the same NIRGUN. Each point represents the mean of 10 fruit from a vine; solid line represents a perfect match. Vertical bar represents least significant difference (LSD) to separate destructively measured means. Horizontal bars represent LSDS to separate NIRGUN predicted means for the specified time.

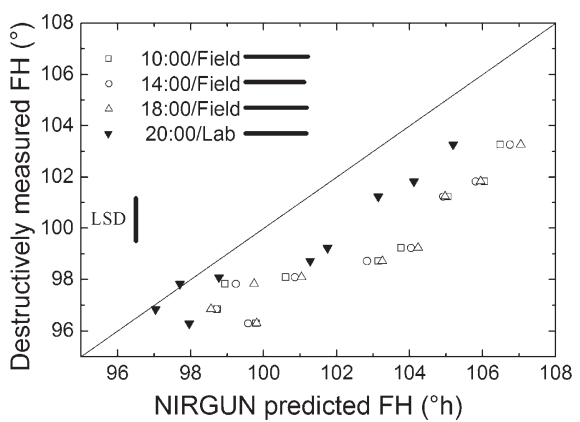

Fig. 8. Comparison between 'Hort16A' kiwifruit average flesh hue $(\mathrm{FH})$ measured destructively and those measurements predicted from NIRGUN assessments in the field or laboratory at different times during a sunny day. The master calibration was established based on the combined data set (see "Methods") measured using the same NIRGUN. Each point represents the mean of 10 fruit from a vine; solid line represents a perfect match. Vertical bar represents least significant difference (LSD) to separate destructively measured means. Horizontal bars represent LSDS to separate NIRGUN predicted means for the specified time.

was at $10^{\circ} \mathrm{C}$ compared with the bias of $-0.31 \%$ DM when the NIRGUN was at $20^{\circ} \mathrm{C}$. Conversely, the biases for SSC and FH were significantly affected by fruit temperature but not instrument temperature (Fig. 9). The magnitudes of temperature effects shown in Figure 9 were much smaller than those shown in Figure 2 , indicating the superior performance of the master calibration model based on the combined calibration data set compared with the first calibration model based on a single data set (Tables 1 and 2).

Model performance in a subsequent year at different ambient light conditions. Predicted values for DM, SSC, and FH under strong ambient light were very close to those predicted under weak ambient light (Fig. 10). Figure 10 also indicated that repeated NIRGUN measurements on the same fruit gave very consistent results $\left(R^{2}>0.95\right)$.

\section{Discussion}

On-vine fruit measurement. On-vine orchard experiments demonstrated that DM, $\mathrm{SSC}$, and FH can be predicted with the same level of precision in the field as in the laboratory. The analysis of variance revealed very similar rankings of means for the nine vines used in the experiment irrespective of whether NIRGUN predictions or destructive measurements were used. However, there was a significant prediction bias associated with many of the NIRGUN results, particularly with what looked like diurnal variation. This means that the accuracy of the NIRGUN prediction in the orchard depends on the time of day at which the measurement is made. Despite that variation, differences between vines were clearly measurable and consistent in a relative sense at any one time and would enable the ready differentiation of vines in terms of fruit maturity/quality. 

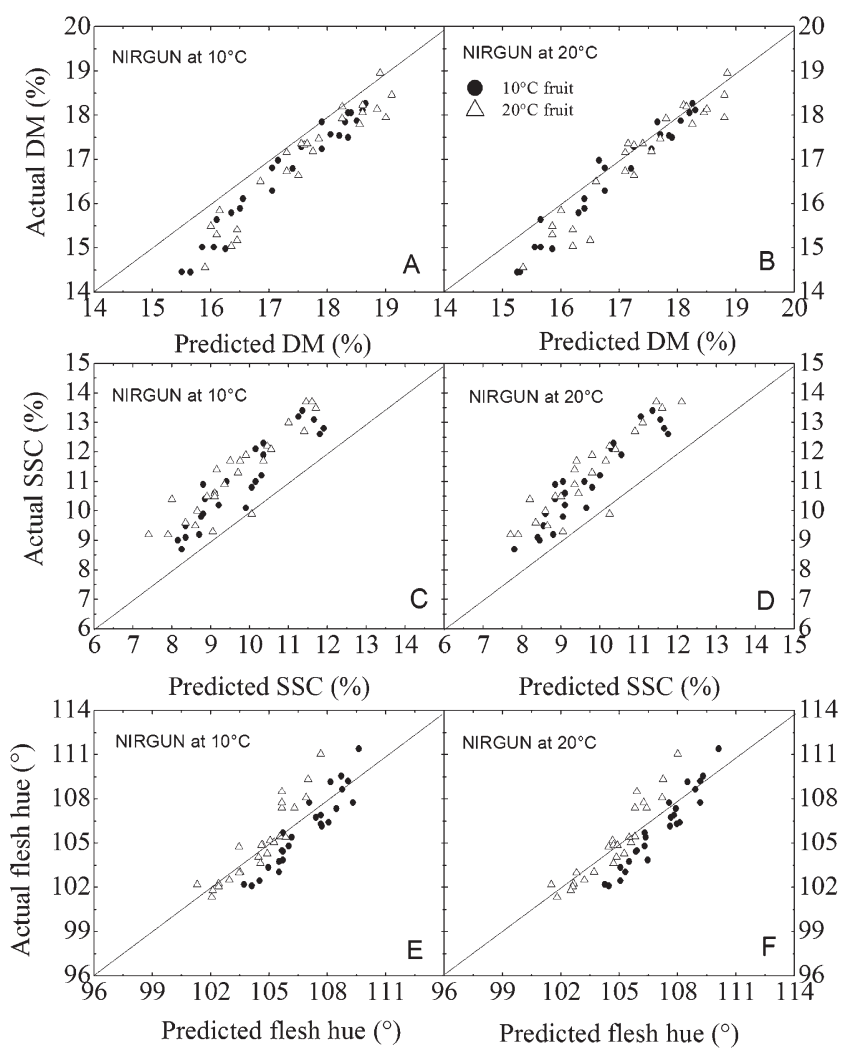

Fig. 9. Effect of instrument and fruit temperature on prediction of 'Hort16A' kiwifruit dry matter, soluble solids content, and flesh hue in 2007 using the master calibration established in 2005 based on the combined calibration data set measured using another NIRGUN.

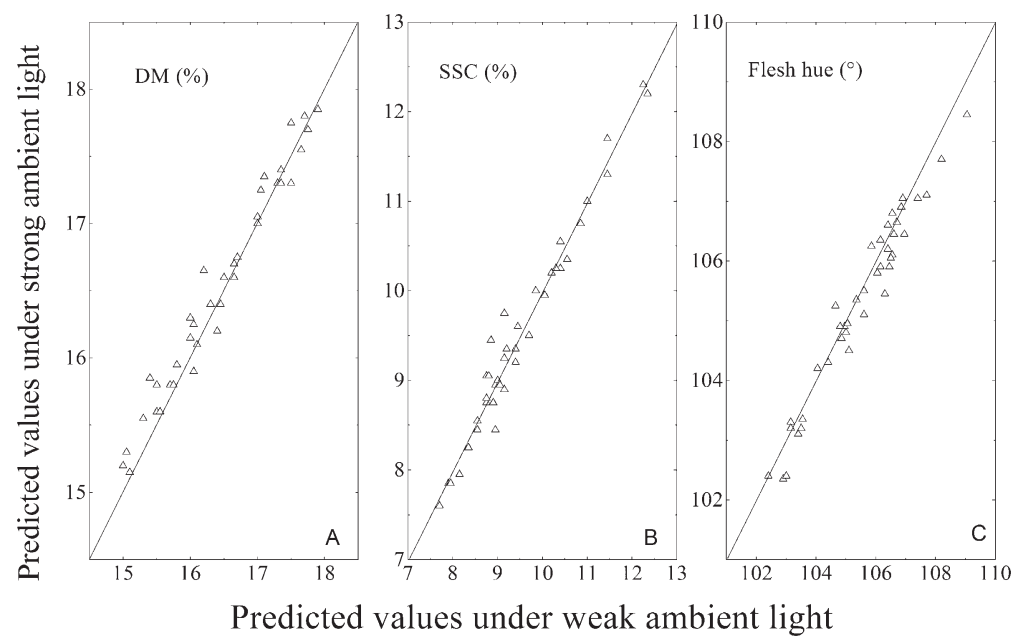

Fig. 10. Effect of lighting on prediction of 'Hort16A' kiwifruit dry matter (DM), soluble solids content (SSC), and flesh hue in 2007 using the master calibration established in 2005 based on the combined data set measured using another NIRGUN. Weak ambient light means near-infrared (NIR) measurement was made under scattered light from windows when all the lights in the laboratory were turned off. Strong ambient light means NIR measurement was made under two 58-W Philips Daylight fluorescent tubes $(\approx 800 \mathrm{~mm}$ distance between fruit and the lights).

The bias might not be a problem, particularly if small subsets of fruit could be efficiently collected and destructively measured. This subset of measurements could then be used to calculate an appropriate adjustment to make the mean NIRGUN predictions match the destructive measurements. Whereas such a strategy could work well for $\mathrm{SSC}$ and $\mathrm{FH}$, in which destructive measurements can be made rapidly, it would seem mental variations or the fruit themselves are not. Certainly the instrument proved very stable at each of the three set laboratory temperatures to which it was equilibrated. The study in 2007 at a combination of two instrument temperatures and two fruit temperatures indicated that instrument temperature could have a significant influence in DM prediction, although the absolute difference between DM predicted with the instrument at 10 or $20^{\circ} \mathrm{C}$ was minor $(0.27 \%$ DM, Fig. $9 \mathrm{~A}-$ B). Instrument temperature did not appear to have any significant influence on predicted SSC and FH (Fig. 9C-F). This suggests that the instrument is at least reasonably stable against variation in temperature for parameters of interest to the kiwifruit industry. The study in 2007 also indicated that the effect of fruit temperature on predicted values was greatly reduced when using the predictive models established in 2005 based on a combined data set collected at a range of temperature and fruit conditions. The bias of DM prediction for $10{ }^{\circ} \mathrm{C}$ fruit was not significantly different from that for $20^{\circ} \mathrm{C}$ fruit. The bias difference between 10 and $20{ }^{\circ} \mathrm{C}$ fruit was statistically significant for predicted SSC and $\mathrm{FH}$, but the difference was only $0.2 \%$ SSC and $1.4^{\circ}$ hue.

The dependence of prediction bias on diurnal time suggests that bias variation is related to environmental factors affecting the fruit such as sunlight flux and temperature. Changes in sunlight flux during the day were not considered likely as a major cause of bias offsets, because all the measurements were made in a mature orchard with heavy and established canopies with little chance of sampled fruit being exposed to direct sunlight. This assumption was further confirmed by the identical prediction results from measurements on the same fruit at different ambient light conditions (Fig. 10). Direct temperature fluctuations also seemed unlikely to be the major factor causing prediction bias, because the calibration data set already included data collected at different temperatures and the bias difference between fruit at 10 and $20{ }^{\circ} \mathrm{C}$ in 2007 (Fig. 9) was much smaller than the difference between diurnal times (Figs. 6, 7, and 8).

We can speculate further that another cause for bias could be fruit water loss during the day. Kiwifruit vines may experience water stress around noon and early afternoon. The high temperature and low relative humidity observed during this time (Fig. 5) may have caused excessive water loss from the fruit. Although fruit water loss is unlikely to result in a $1.2 \%$ increase in DM or a $0.9 \%$ increase in SSC on a whole-fruit basis, such increases in DM and SSC could be possible within the localized skin tissue regions from where NIRGUN measurements were made. Predicted FH values in the field measurement were over $1.7^{\circ}$ higher than that predicted in laboratory conditions at $2000 \mathrm{HR}$ and $3^{\circ}$ higher than the values measured destructively. The difference among the three field measurements was relatively small (less than $0.3^{\circ}$ ). The large prediction bias of the field 
measurements may be related to excitation of chlorophyll during the day and the fact that the destructive color measurement is taken at a depth of $\approx 2 \mathrm{~mm}$ or more, whereas the NIR includes information from more superficial regions. Certainly, the superficial color of 'Hort16A' kiwifruit is much greener than the interior coloration and can have a substantive influence on color measurement (B. Jordan and M. Loeffen, personal communication). Moisture on fruit surfaces may also be contributing. The thickness of fruit tissue, which is effectively measured using the NIRGUN, might be reduced as the fruit surface dries out.

Comment on flesh color measurement. Analysis of pigments across different species and genotypes of genus Actinidia indicated that the yellow flesh color of 'Hort16A' kiwifruit is mainly the result of the absence of chlorophylls in the fruit rather than a significant increase in the carotenoid concentration (McGhie and Ainge 2002; Montefiori et al., 2009). Therefore, it was expected that chlorophyll absorption region $\approx 680 \mathrm{~nm}$ would be important for developing calibration for flesh color. However, extending wavelength range down to $650 \mathrm{~nm}$ did not result in better calibration for $\mathrm{FH}$ compared with the calibration based on the default wavelength range (data not shown). Therefore, the master calibration was based on the default wavelength range of 700 to $950 \mathrm{~nm}$ (general users do not have access to the "Professional Ca_Maker" for wavelength extension).

The master calibration for $\mathrm{FH}$ used five wavelengths ranging from 732 to $948 \mathrm{~nm}$ (Table 2), indicating the correlation between FH and carbohydrates. Indeed, FH was found to be negatively correlated with dry matter content $\left(R^{2}=0.56\right.$ based on the combined calibration data set to develop the master calibration). This may be attributed to the reflecting and scattering effect of starch granules that account for up to $50 \%$ of the dry matter during the harvest season.

Model transfer between instruments in different years. The calibration models developed in 2005 using one NIRGUN were able to predict DM, SSC, and FH of fruit harvested in 2007 using another NIRGUN with SEP of $0.27 \%$ to $0.39 \% \mathrm{DM}, 0.60 \%$ to $0.77 \% \mathrm{SSC}$, and 0.68 to $1.00^{\circ}$ hue, respectively (Fig. 9). Predicted values from the NIRGUN at $20{ }^{\circ} \mathrm{C}$ correlated with measured values with $R^{2}$ of 0.95 for $\mathrm{DM}, 0.82$ for $\mathrm{SSC}$, and 0.85 for FH (Fig. 9). The prediction bias observed in 2007 (Fig. 9) was not substantively different from that observed in 2005 under laboratory conditions (2000 HRh/laboratory results in Table 3). These model transfer results are similar to those achieved with a benchtop NIR instrument (Clark and McGlone, unpublished data). This is very encouraging because it indicates that the calibration models can be transferred to other instruments for measurement in subsequent years. Usually, the calibration model would need to be updated to cope with the variability between fruit produced from different years. Such a training process requires large data sets that cover a wider range of variability in both fruit and measurement conditions. The calibration software currently available with the NIRGUN can only hold 1000 observations and there is a maximum of five wavelengths that can be selected for calibration. This limits the ability of operators to use robust calibration models. For the NIRGUN to provide robust measurements with a wide variety of orchards and environmental conditions, improvements to the calibration software are needed so that these limitations can be overcome.

Calibration transfer between the NIRGUNs changed the regression slope as well as the bias (Fig. 9). This means that corrections cannot be made simply by just applying a fixed offset. This problem could be resolved using sophisticated calibration procedures for more accurate prediction. However, the model and instrument as they stand now would be useful to detect relative differences between batches of 'Hort16A' kiwifruit where measurements are made under similar conditions, either in the field when fruit temperature is stable or in a temperature-controlled laboratory situation.

\section{Conclusion}

The precision of the NIRGUN in predicting DM, SSC, and hue in 'Hort16A' kiwifruit is similar to the level reported for standard laboratory benchtop instruments. The NIRGUN measurements can be used to distinguish fruit from different vines. For this purpose, then, the predictive models developed using one NIRGUN could be transferred to another unit for measurements in a subsequent year. However, this is only possible in a relative sense in which all fruit measurements are made under the same measurement conditions, either within a short period of time in the field or in a laboratory under set conditions. This is because the accuracy of NIRGUN predictions is affected by significant and variable bias offsets, especially for field measurements made while kiwifruit are on the vine. Bias corrections are possible and feasible for some quality attributes by taking small subsets of fruit for destructive measurement.

\section{Literature Cited}

Aoki, H., T. Tanabe, and T. Akinaga. 2010. Pre and postharvest data collecting system using the compact NIR analyzer. Acta Hort. 864:299304

Clark, C.J., V.A. McGlone, H.N. De Silva, M.A. Manning, J. Burdon, and A.D. Mowat. 2004. Prediction of storage disorders of kiwifruit (Actinidia chinensis) based on visible-NIR spectral characteristics at harvest. Postharvest Biol. Technol. 32:147-158

Costa, G., M. Noferini, G. Fiori, and O. Miserocchi. 2002. Determination of indications of harvest and fruit quality in kiwifruit. Rivista di Frutticoltura e di Ortofloricoltura 64:20-23.

Feng, J., K.M. Maguire, and B.R. MacKay. 2002. Effects of package and equilibration time on physiochemical attributes of 'Hayward' kiwifruit. Acta Hort. 599:149-155.

Golding, J.B., S. Satyan, C. Liebenberg, K. Walsh, and W.B. McGlasson. 2006. Application of portable NIR for measuring soluble solids concentrations in peaches. Acta Hort. 713:461-464.

Hopkins, D.W. 2001. What is a Norris derivative? NIR News 12:3-5.

Khuriyati, N., T. Matsuoka, and S. Kawano. 2004. Precise near infrared spectral acquisition of intact tomatoes in interactance mode. J. Near Infrared Spectrosc. 12:391-396.

Kusumiyati, T., M. Akinaga, Tanaka, and S. Kawasaki. 2008. On-tree and after-harvesting evaluation of firmness, color and lycopene content of tomato fruit using portable NIR spectroscopy. J. Food Agr. Environ. 6:327332.

Martin, R.A. and P. Luxton. 2005. The successful commercialization of ZESPRI ${ }^{\mathrm{TM}}$ gold kiwifruit. Acta Hort. 694:35-40.

McGhie, T.K. and G.D. Ainge. 2002. Color in fruit of the genus Actinidia: Carotenoid and chlorophyll compositions. J. Agr. Food Chem. 50:117121.

McGlone, V.A., R.B. Jordan, R. Seelye, and P.J. Martinsen. 2002. Comparing density and NIR methods for measurement of kiwifruit dry matter and soluble solids content. Postharvest Biol. Technol. 6:191-198.

Montefiori, M., T.K. McGhie, I.C. Hallett, and G. Costa. 2009. Changes in pigments and plastid ultrastructure during ripening of green-fleshed and yellow-fleshed kiwifruit. Sci. Hort. 119:377387.

Saranwong, S., J. Sornsrivichai, and S. Kawano. 2003a. Performance of a portable NIR instrument for Brix value determination of intact mango fruit. J. Near Infrared Spectrosc. 11:175181.

Saranwong, S., J. Sornsrivichai, and S. Kawano. 2003b. On-tree evaluation of harvesting quality of mango fruit using a hand-held NIR instrument. J. Near Infrared Spectrosc. 11:283294.

Schaare, P.N. and D.G. Fraser. 2000. Comparison of reflectance, interactance and transmission modes of visible-near infrared spectroscopy for measuring internal properties of kiwifruit (Actinidia chinensis). Postharvest Biol. Technol. 20: 175-184.

Zude, M., M. Pflanz, C. Kaprielian, and B.L. Aivazian. 2008. NIRS as a tool for precision horticulture in the citrus industry. Biosystems Eng. 99:455-459. 